\title{
Financial Inclusion in the Digital Age, its Role and Impact on Economic Growth
}

\author{
Article by Folasade B. Femi-Lawal \\ Principal Manager, First Bank of Nigeria Limited, Nigeria \\ E-mail: Omotoke.Norine@gmail.com
}

\begin{abstract}
Globally, Financial Inclusion (FI) and Digital Financial Services (DFS) have become a life-blood and key driver of socio-economic growth and development on the backdrop that economies are dependent on financial services to attain advancement. The paper explored the role of Mobile Money Services (MMS), also known as DFS in enhancing access to financial services.

The research was driven by the increasing mobile network spread, the under-served, ubiquity/ penetration of mobile devices amongst both the poor and low-income earners, factors affecting FI, fees which are disincentive to users, introduction of cashless Nigeria by the Central Bank of Nigeria as well as the emergence of Mobile Money Services in 2009. An in-depth analysis of MMS in driving FI and paradigm shift in traditional payment systems was embarked on and focused on issues associated with services provided MMS Operators viz transaction fees, transaction value and count; stakeholders within the ecosystem, user experience and security of funds, policy and regulation on financial services delivery as well as inclusive participation of the government, regulatory bodies and infrastructure providers.

The findings showed that while the MMS have a huge potential to drive DFS in Nigeria, it would require deliberate actions by all stakeholders to establish an appropriate solution capable of transforming the economy and also the contribution of MMS to FI in reducing the financially excluded is critical to the nation. Advancing this therefore, the government and other critical stakeholders would need to create a framework that will enhance access to financial services.
\end{abstract}

Keywords: Digital Financial Services (DFS); Financial Inclusion.

\section{Introduction}

Financial inclusion (FI) in itself is access to basic, useful and affordable financial products and services that meet the needs of the excluded (unbanked and under-banked). Such needs include-payments, savings, credit and insurance, delivered to them in a sustainable and suitable way. This is driven by innovation and technology, e.g. mobile devices. And its implementation and adoption will culminate in bringing the excluded to the mainstream of banking and result into economic development as more monies are expended and saved.

In recent time, Nigeria has witnessed proliferation of mobile phones and growth in mobile network spread. For instance, in the country, there are over 143 million active mobile lines with a teledensity of 102.2 (Nigeria Communications Commissions, NCC, June 2017) and still growing. Virtually every home has, at least, a mobile handset. Thus, emergence of mobile telephony especially digital technologies such as social media (especially the millennials), online games and mobile applications, multimedia, productivity applications, cloud computing, and mobile devices have the potential to resolve lack of access to basic financial services for both unbanked and under-served.

According to EFINA Access to Financial Services (2017), over $60 \%$ of working adults have no access to the types of formal financial services delivered by regulated financial institutions. The availability of basic financial services that meet the specific demands or needs of households without boundaries is a key tool to reducing financial exclusion and driving economic growth.

However, recent events have hampered this progress. Hence, this research/ study. The study is aimed at;

1. Evaluating the relevance of MMS in Financial Inclusion of the under-served

2. Strategies/ best approach to reduce financial exclusion and, 
DOI: $10.21522 /$ TIJAR.2014.04.02.Art018

ISSN: $2520-3088$

3. Assessing the impact of FI on economic growth and development.

\section{Problem statements}

Inspite of the increasing penetration of mobile phones and growth in mobile network spread, there have been concerns on the number of adults that are without bank accounts. These concerns are associated with:

a) Cultural and religious challenges, particularly Northern Nigeria, where women are constrained to their homes and deprived of appearing in the public;

b) The challenges brought about by high illiteracy and technology used for mobile financial services;

c) Lack of appropriate digital financial products and services that suit their need, e.g. micro-credit, micro-insurance

d) Lack of trust resulting from cyber-security threats to financial transactions via digital platforms from illegal activities.

e) Stringent requirements to access financial services by banks which include but not limited to mode of identification, utility bill, Bank Verification Number (BVN), amongst others.

f) Proximity to the location of financial services. Most of the underserved live in remote locations, where vehicular mobility is limited.

g) The high cost of building and operating brick-and-mortar bank branches has been a major obstacle for extending financial services to the poor/ low income households

h) Nigeria being Africa's most populous country with an estimated population of over 180 million, and out of 96.4 million adults, 40 million adults representing $41.6 \%$ are still financially excluded (EFInA Access to financial inclusion survey 2016).

i) The Proportion of Nigerian adult with access to formal and informal financial services shrunk marginally from $60.4 \%$ in 2014 to $58.5 \%$ in 2016 due to a slight reduction in appeal and coverage of informal services (EFInA Access to financial inclusion survey 2016).

All of the aforementioned have culminated in consumers having apathy to bank products and services and lacking full confidence in the security of using mobile technology to transactions.

\section{Existing solution}

One potentially effective way to accelerate financial inclusion and deliver a broader set of benefits is payments digitization. According to KPMG in its publication on "Understanding the Value Proposition of Fintech in Nigeria", Innovation and technology have brought about a radical change in traditional financial services. The world has seen the emergence of more than 12,000 start-ups and massive global investment of USD 19 billion in 2015 in the FinTech space.

Presently, several digital financial services solution abound in the country to extend basic financial services to both unbanked and under-banked, and prominent amongst these are Mobile Money Service and Unstructured Supplementary Service Data (USSD) banking. The MMS is considered the most appropriate for the financial excluded, in that, users do not have own a bank account to carry out financial transactions. All that is required is virtual account, aka, ewallet. On the other hand, USSD banking requires users to have a bank account before they can initiate a financial transaction. Though, the unbanked can create a $1^{\text {st }}$-tier account that does not require mandatory account documentation, but it is important a customer registers for $\mathrm{BVN}$ to conduct any meaningful transactions.

On the basis of this, the MMS is now considered as the most used by the government and social welfare scheme campaigners such as UNICEF, Bill and Melinda Gates Foundation, USAID/AIDS, Catholic Relief Services (CRS) amongst others (in Nigeria) to drive financial inclusion. Since inception, Mobile Money Operators (MMOs) have established and created innovative digital products and services such as airtime top-up, fund transfer, bills payment, tokenization, purchases, conditional cash transfer schemes (cash disbursements) and retail payments. These services are not tied to any bank operative account. Rather, customers are able to open virtual account anywhere and anytime without, necessarily, visiting any bank branch, or banks could bulk register the beneficiaries of such schemes.

However, the use of digital financial services by previously excluded households and businesses brings not only benefits but also risks, due in part to the characteristics of a typical poor customer (inexperienced 
with formal financial services and unfamiliar with consumer rights). Some of the risks are new while others, although well known, may take on different dimensions in the financial inclusion context. According to GSMA recent report, of the 4.8 billion Global Mobile Subscribers, 3.6 billion are located in low and middle income countries.

Examples where the MMS solution was deployed successful in Africa include the following;

a) Mobile phones are increasingly used for payments and collections with companies like PayAttitude, Visa and MasterCard offering contactless payments solutions. Other FinTechs are also expanding their payment options to create omni-channels for the customer. Virtually wallet (mobile money is on the fastest growing options for the unbanked segment).

b) Another example of digital financial inclusion in the digital age is the Kenya's MPesa. Its growth has shown the potentials of collaborative partnerships within the financial \& telecoms sectors and its dramatic transformational effect on money transfer \& payment systems in Africa.

c) Approximately 255 mobile money services were operating across 89 countries in 2014. They are now accessible in more than 60 percent of developing markets. Sub Saharan Africa is the region where mobile money is most widely spread, followed by Southeast Asia and Latin America (Forbes, 2015).

d) In Nigeria for instance, several financial services providers, particularly the banks, are aggressively driving financial inclusion using both digital technologies and agent banking. The major players are FirstBank of Nigeria Ltd, GTBank, StanbicIBTC, Ecobank and Access Bank.

e) These banks have used digital innovation to extend basic financial services to the unbanked and under-banked. Today, Donors like EFINA, UNICEF, Catholic Relief Services/ USAID, World Bank and the Federal Government of Nigeria have adopted the mobile money services to drive financial inclusive participation.

f) Specifically, FirstBank Nigeria Ltd, is not new to Digital Financial Services. Leveraging technology and innovation, in 2013, partnered UNICEF to implement its mobile money solution for the disbursement of payments to rural women in the Northern part of Nigeria on Polio Eradication Programme (PEP). Between June 2013 to May 2014, the bank disbursed about N880M to over 25,000 (cumulatively) rural women located in 536 wards across 82 Local Government Areas in Seven (7) Northern States (Bauchi, Kaduna, Kano, Katsina, Kebbi, Sokoto and Zamfara). The participants were Polio Survival Groups (PSGs) "the physically challenged", Volunteer Community Mobilizers (VCMs) and Volunteer Ward Supervisors (VWS). As the pioneer bank of this innovative financial services, it was award "the Best Mobile Money Operator in 2014 by EFInA".

\section{Limitations}

In spite of the social impact and role of MMS in expanding financial inclusion and enhancing economic development, it is faced with technology and innovation, ICT, infrastructure, economic, communication and regulatory limitations. These are:

- Lack of trust/ confidence in financial products and services.

- Poverty as a result of unemployment and under-employment

- Inadequate network coverage in remote locations, where financial inclusion is required to support their socio-economic activities such as farming and petty trading.

- Inadequate infrastructure to support the scheme

- Interoperability challenge. Difficulty in inter-scheme financial transactions still persist and must be addressed to facilitate the desired growth.

- Socio-cultural complexities are also a major factor inhibiting financial inclusion. Most cultures in Nigeria limit public presence of the female folks.

- Low level of literacy about financial products and services.

\section{Achievements}

Without a doubt, MMS has positively impacted financial inclusion and economic development. Notwithstanding the limitations advanced above, households and businesses in Nigeria now use digital payments and financial accounts to interact seamlessly and efficiently, unleashing large gains in 
DOI: $10.21522 /$ TIJAR.2014.04.02.Art018

ISSN: $2520-3088$

productivity and investment, and prompting greater financial inclusion. Therefore, with the vision of reaching millions of adults and new customers in Nigeria, Financial Institutions and Financial Technology Companies (FinTech), have started offering digital financial services (DFS) for the financially excluded and under-banked, leveraging on the methods that were implemented and used for years to advance access channels for those who are already served by banks and other financial institutions.

Beyond this, Nigeria has recorded huge successes in financial inclusion through MMS. Examples include

a) FirstBank of Nigeria Conditional Cash Transfer (CCT) partnership with UNICEF. Over N800 million was disbursed to over 8,000 beneficiaries across 8 Northern States in Nigeria, namely, Bauchi, Kaduna, Kano, Katsina, Kebbi, Sokoto and Zamfara. These beneficiaries comprised of Volunteer Community Mobilizers (VCM), Volunteer Ward Supervisors (VWS), Polio Survivor Groups (PSG). The FirstBank mobile money solution (Firstmonie) was deployed to cater for their monthly stipends for a period of 12 months (June 2013 to June 2014). This partnership resulted into beneficiaries opening bank accounts. Particularly, beneficiaries in Kaduna, Kano and Sokoto are well positioned now to use financial products and services.

b) Another achievement of FirstBank's Firstmonie MMS is the successful deployment of stipends to CRS beneficiaries in Kebbi and Sokoto States

c) Finally, partnership with New Incentives (All Babies Are Equal) helped women living with HIV/AIDS in some select States (Cross Rivers, Akwa Ibom, Anambra and Abuja) resulted in serving this segment with the bank's financial services. Although, Cash tokenization was used to pay these women.

\section{Methods}

Nigeria is used as a case study to advance this discuss. Nigeria, located in West Africa Sub-Region, is the most populous country in Africa and has $2.5 \%$ of the world population with an estimated population of over 192 million. Nigeria is a multi-religion and ethnic country with 6 major geo-political zones, namely; North East, North West, North Central, South East, South-South and South West.

Experiment was carried out based on the following methods:

a) A priori knowledge derived from my instinctive skills.

b) Posteriori knowledge, derived from my experience driving digital banking and mobile financial services in FirstBank. With over 5 years' cognate experience, I have driven and delivered several DFS projects which are today considered as the fastest growing mobile payment in West Africa.

c) Press and journal researches.

Statistical method adapted is factor and descriptive analysis. Statistical data were collected from different journals and desk research to analyse and summarize my findings.

\section{Results}

The study revealed that growing mobile network spread and penetration of mobile handsets have resulted into establishing regulated agent network, more agents are now available in key locations to serve the unbanked and under-banked, increased bank accounts, increased number of MMS customers and growing conditional cash transfer schemes by NGOs and Governments.

Thus, the proliferation of mobile money services does raise the need for banking and telecom regulators to work together to allow the ecosystem work without interference. It is also advanced here that as mobile money services continue to expand more proactive policies are required to ensure that the market can continue to grow and serve local consumers, which would lead to growth in economic activities.

It was also observed that Fintechs have been active across the value chain of the Nigerian Banking space and Financial Services Institutions. Example is the Interswitch Financial Inclusion Services (IFIS), a licensed Agent Network Operator. Nigerian Banks are beginning to take a strategic and structured approach such as Agent Banking and Mobile Money Agent in engaging the Fintech Community. Digital Financial Services have become a platform for extending basic financial services to the poor and the banked segment, real time and anywhere. 
Also in with recent study by PWC, FinTechs are redrawing the competitive Financial Services landscape and blurring the lines that define players in the sector. Their offerings range from competing financial services such as alternative lending, to additive solutions atop existing banking services, to enabling technologies for the banks themselves. Capitalizing on the latest mobile, cloud and digital technologies, Nigeria is increasingly becoming home to many FinTech firms who are trying to shake up and be accretive to the banking value chain (Price Water - Price Waterhouse Coopers, 2017).

\section{Discussions}

Digital Financial Service is not only seen as a tool for solving the problem of proximity to the locations (physical distance), but also a platform to innovate and reach the target market. Today the unbanked and under-banked populations are increasingly gaining access to financial services through digital channels, thanks to global financial inclusion drive by organizations such as Bill \& Belinda Gates Foundation, United Nations, World Bank, amongst others.

Financial Institutions (Banks, microfinance), Mobile Network Operators (MNOs), and third party providers (such as OEMs) are leveraging penetration of mobile phones, point-of-sale terminals, together with networks of mobile money agents, to offer basic financial services at greater convenience, scale and affordable price than what traditional banking offers.

The Central Bank of Nigeria has defined a strategy that sets clear target for financial inclusion which is to decrease financial exclusion from $40 \%$ in 2010 to $20 \%$ in 2020. The Financial Inclusion Strategy of the Federal Government of Nigeria clearly states that "All Nigerian adults, in particular the low income group, participate in a formal financial system that sustainably provides a suite of financial products that are affordable and accessible, thus reducing poverty and improving household economic wellbeing"

\section{Conclusion}

From the foregoing, it is becoming increasingly clear that for the financially excluded to be provided access to basic financial services together with addressing financial exclusion will require an all-inclusive and systematic tactic on the part of financial services providers and regulators in driving top-of mind awareness (TOMA) about financial products and services, education, and advice on how to effectively manage their funds, safety and reliability of infrastructures, driving savings culture and affordable microcredit that would improve their economy which will subsequently impact economic development.

Therefore, Financial Institutions and Fintech would have to establish and create specific but innovative strategies to expand the scope of their products so as to stimulate and facilitate financial inclusion. One of the ways in which this can be achieved in a cost-effective manner is through forging linkages with microfinance institutions, NGO's and local communities. Banks should give wide publicity. Technology can be a very valuable tool in providing access to banking products in remote areas. ATMs cash dispensing machines can be modified suitably to make them user friendly for people who are illiterate, less educated or do not know English. And one of such approach is Human Teller Machine (Mobile Agents).

From the above discourse, it is apparent that digital technology and innovations are key drivers of expanding the businesses of the banks and other financial instituions. Furthermore, with increasing threats of Fintech, Nigerian Banks are now left with no choice but to 'innovate or die' with the associated requirements to invest in these innovations and technologies for the provision of payment systems that would address the issues earlier identified.

As more people are financially included, financial institutions will experience multiplier effect on their businesses. As investments thrive, the unemployed/ unbanked are economically engaged with jobs that will improve their economic life. These and other socio-economic initiatives will help the financial and technology industries develop new services and achieve the UN Sustainable Development Goals (SDGs).

Furthermore, as more participants are involved in driving financial inclusion, it is believed that large numbers of the unbanked will gradually decline. I recommend that the private sector should collaborate with Financial Inclusion Campaigners (CGPA, GSMA) to advance and champion the discourse that will culminate in new ways of thinking and innovation in financial inclusive products and services, which will 
DOI: $10.21522 /$ TIJAR.2014.04.02.Art018

ISSN: $2520-3088$

help the underserved in Nigeria and other emerging economies to achieve better financial services delivery whilst improving cost to serve.

Finally, with greater adoption of mobile devices and spread of mobile networks, together with the desire of Fintechs and Financial Institutions to drive digital financial services together, the financially excluded will be provided with the needed platform to improve their well-being. This will further push the frontiers of retail banking through innovations in digital financial inclusion with attendant economic development.

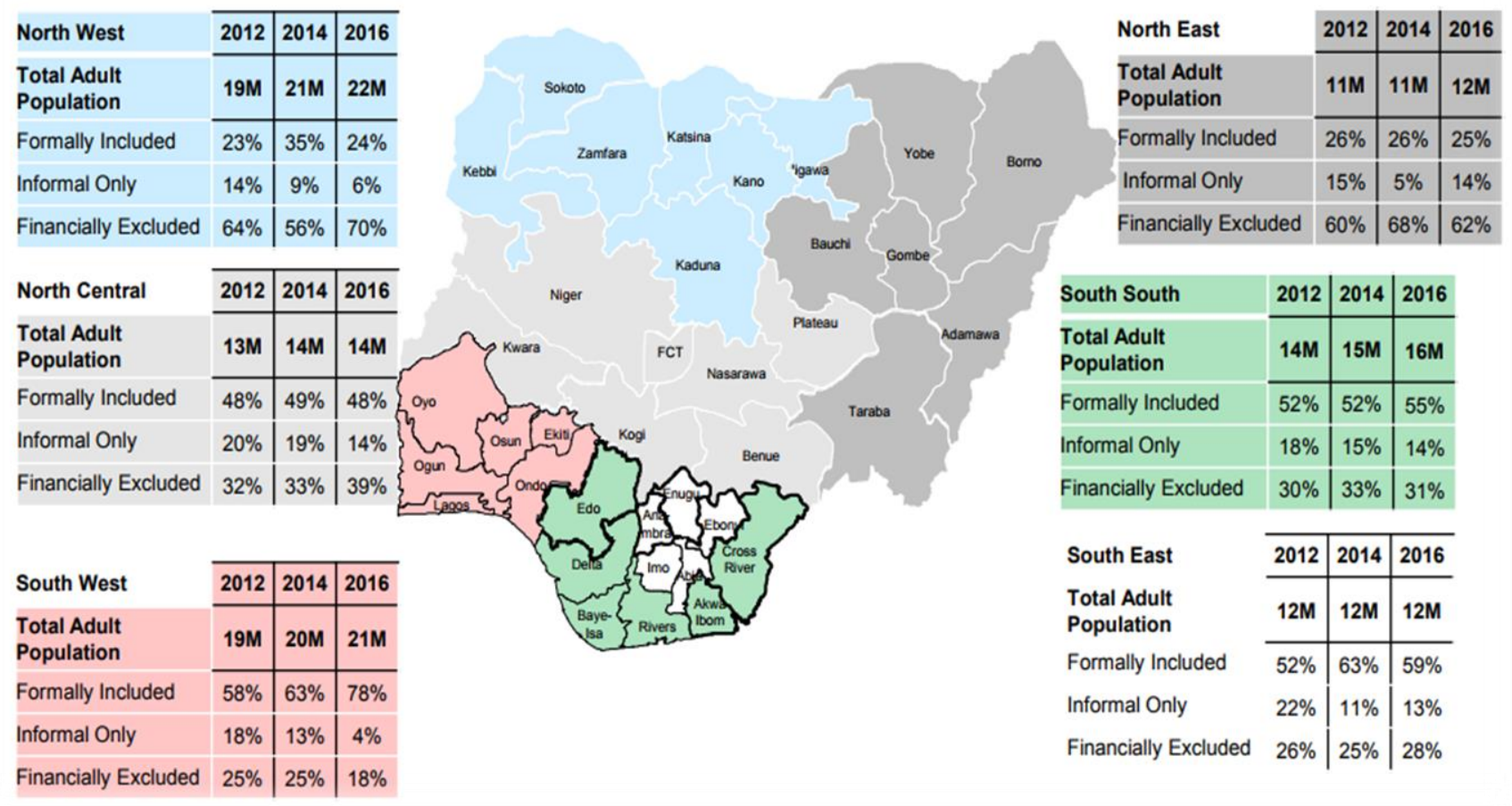

Figure. 1. Financial access performance across geo-political zones

Source: EFINA Access to Financial Services Survey 2016 
Texila International Journal of Academic Research Volume 4, Issue 2, Dec 2017

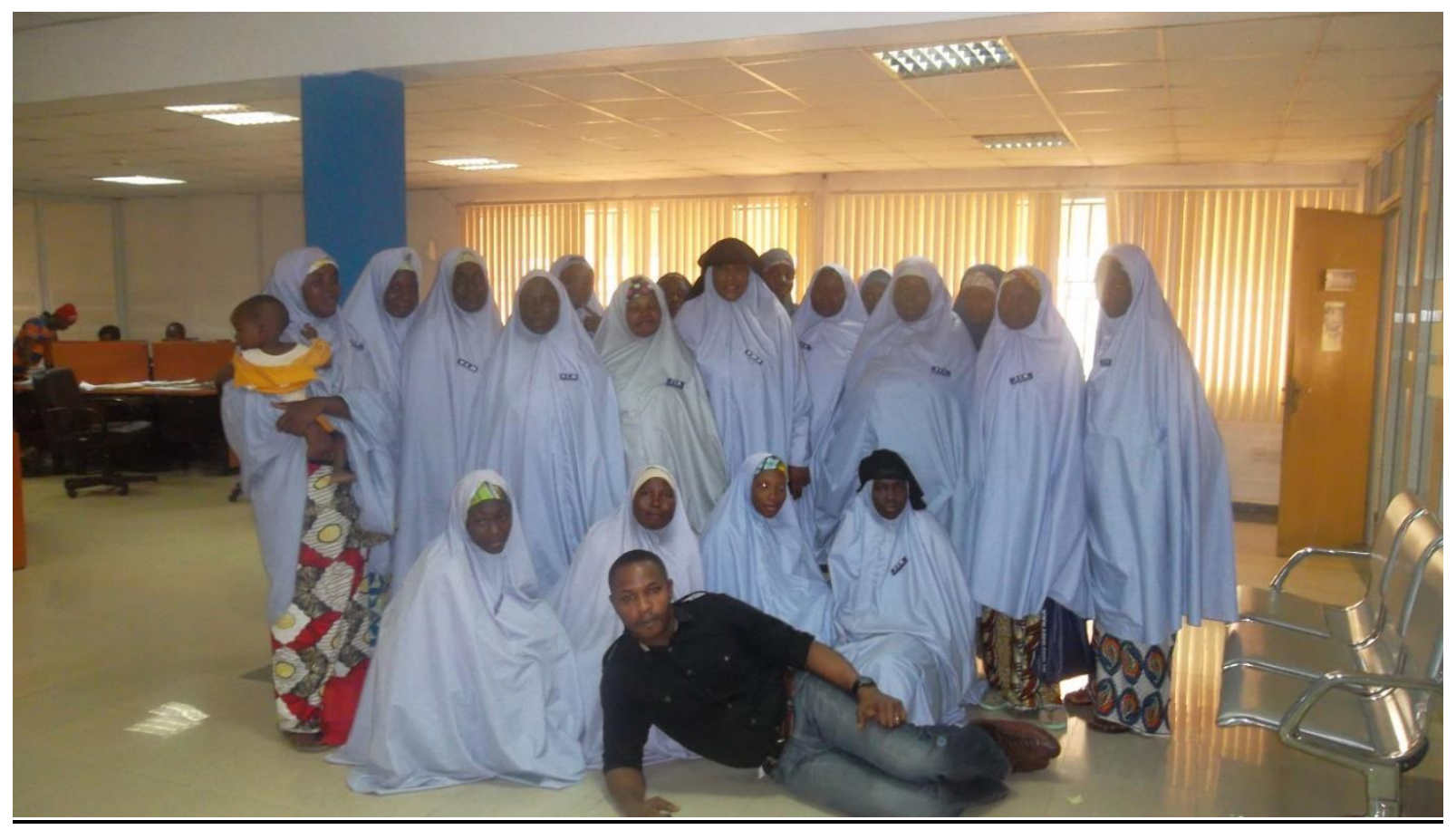

Figure. 2. Disbursement scheme with UNICEF (Zaria, Kaduna, Nigeria)

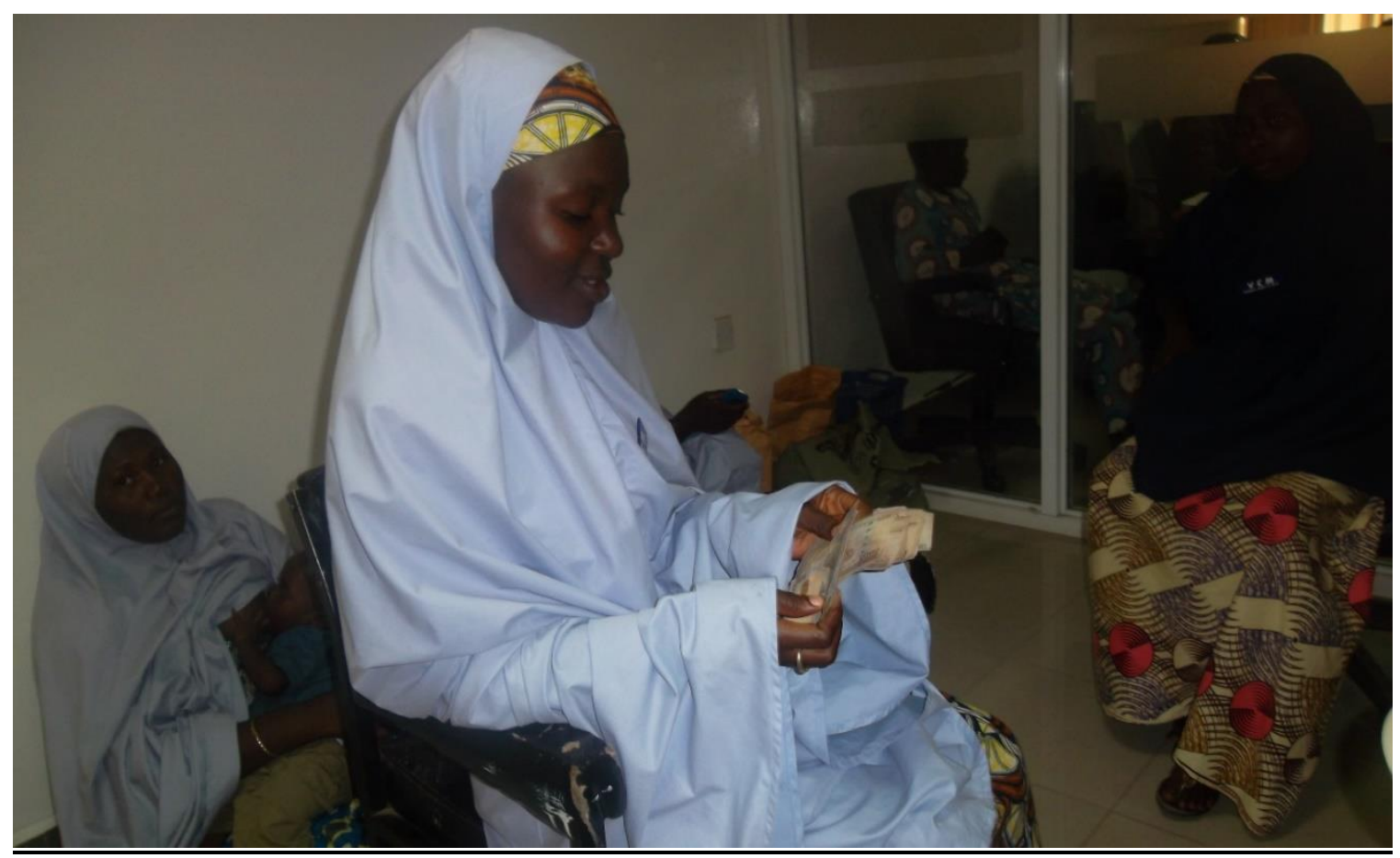

Figure. 3 A VCM confirming the amount paid to her by Firstmonie Agent (Zaria, Kaduna) 
DOI: $10.21522 /$ TIJAR.2014.04.02.Art018

ISSN: $2520-3088$

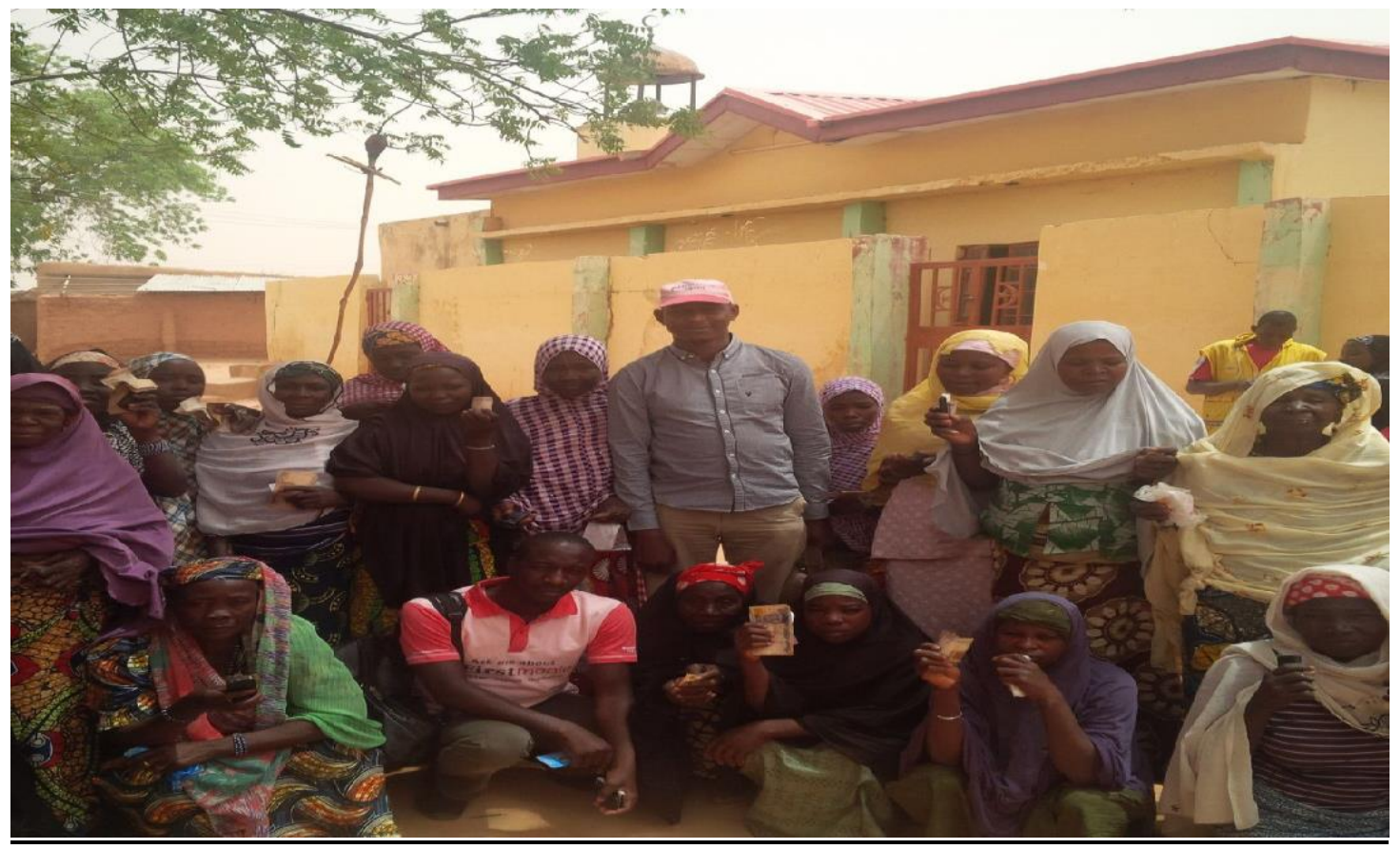

Figure. 4 Catholic relief services disbursement scheme with firstbank (Sokoto, nigeria)

Mobile Money Services (MMS)
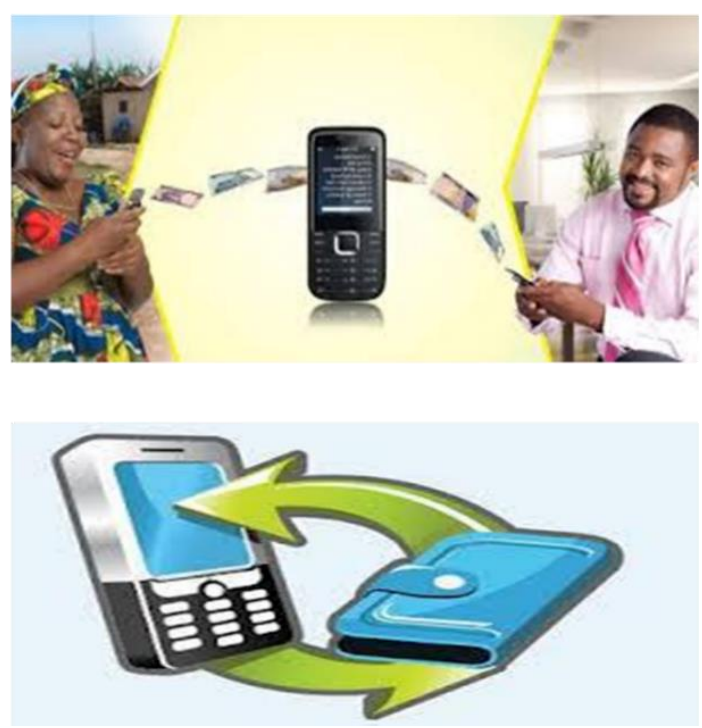

$\square$ USSD Banking
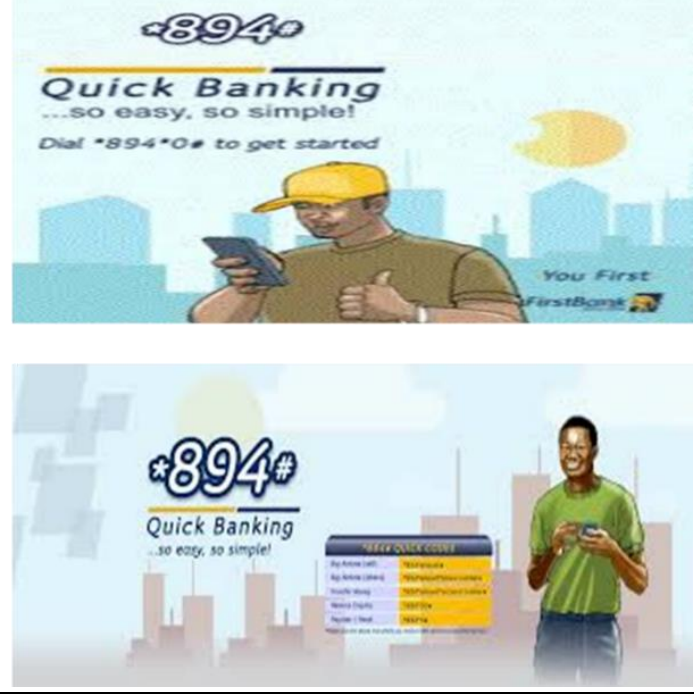

Figure. 5 Existing digital financial services solution in nigeria

\section{References}

[1]. Daniel Runde (Forbes), August 2015: M-Pesa and the Rise of the Global Mobile Money Market.

[2]. Duncombe, R, 2009. "Assessing the potential for Mobile Payments in Africa": Approaches and Evidence from Uganda. Development Informatics Working Paper Series Paper No. 41. Centre for Development Informatics, Institute for Development Policy and Management, University of Manchester.

[3]. Enhancing Financial Innovation \& Access (EFInA), July 2017: Access to Financial Services in Nigeria 2016 Survey.

[4]. Global Mobile Systems Association (GSMA), 2017: The Mobile Economy West Africa. 
[5]. Global Mobile Systems Association (GSMA), 2014: State of the Industry; Mobile Financial Services for the Unbanked.

[6]. KPMG November 2016: Fintech in Nigeria, "Understanding the Value Proposition of Fintech in Nigeria".

[7]. McKinsey \& Company, January 2017: "A Future that Works: Automation, Employment, and Productivity".

[8]. Nigeria Communication Commission: Subscriber Statistics, June 2017:

http://www.ncc.gov.ng/stakeholder/statistics-reports/subscriber-data.

[9]. National Bureau of Statistics "NBS", 2017. Nigeria Population/ Demography. www.nbs.gov.ng.

[10]. PricewaterhouseCoopers, February 2016: Disruption of Nigeria's Financial Service sector by FinTechs is underway.

[11]. The Consultative Group to Assist the Poor (CGAP), March 2015: Digital Financial Inclusion. 